\title{
Dot1 binding induces chromatin rearrangements by histone methylation- dependent and -independent mechanisms
}

\author{
Iris JE Stulemeijer ${ }^{1}$, Brietta L Pike ${ }^{2}$, Alex W Faber ${ }^{1}$, Kitty F Verzijlbergen ${ }^{1}$, Tibor van Welsem', Floor Frederiks ${ }^{1}$, \\ Tineke L Lenstra ${ }^{3}$, Frank CP Holstege ${ }^{3}$, Susan M Gasser ${ }^{2}$, Fred van Leeuwen ${ }^{1,3^{*}}$
}

\begin{abstract}
Background: Methylation of histone H3 lysine 79 (H3K79) by Dot1 is highly conserved among species and has been associated with both gene repression and activation. To eliminate indirect effects and examine the direct consequences of Dot1 binding and H3K79 methylation, we investigated the effects of targeting Dot1 to different positions in the yeast genome.

Results: Targeting Dot1 did not activate transcription at a euchromatic locus. However, chromatin-bound Dot1 derepressed heterochromatin-mediated gene silencing over a considerable distance. Unexpectedly, Dot1-mediated derepression was established by both a H3K79 methylation-dependent and a methylation-independent mechanism; the latter required the histone acetyltransferase Gcn5. By monitoring the localization of a fluorescently tagged telomere in living cells, we found that the targeting of Dot1, but not its methylation activity, led to the release of a telomere from the repressive environment at the nuclear periphery. This probably contributes to the activity-independent derepression effect of Dot1.
\end{abstract}

Conclusions: Targeting of Dot1 promoted gene expression by antagonizing gene repression through both histone methylation and chromatin relocalization. Our findings show that binding of Dot1 to chromatin can positively affect local gene expression by chromatin rearrangements over a considerable distance.

\section{Background}

Post-translational modifications of histone proteins are intimately involved in regulation of gene expression [1]. Histone modifications can influence chromatin structure either directly or via proteins that specifically recognize the modified histones [1]. Methylation of histone H3 lysine 79 (H3K79) by Dot1 (also known as KMT4, DOT1L, mDot1 and grappa) is a histone modification that is highly conserved between species [2]. Several studies have linked Dot1 to gene activation. For example, methylated H3K79 is predominantly located in euchromatic regions of the genome [2-8], and Dot1 has been implicated in reactivation of tumor-suppressor genes upon DNA demethylation [9]. Furthermore, in human leukemias bearing chromosomal translocations at the

\footnotetext{
* Correspondence: fred.v.leeuwen@nkinl

'Division of Gene Regulation, Netherlands Cancer Institute, Netherlands Proteomics Centre, Plesmanlaan 121, 1066CX Amsterdam, The Netherlands Full list of author information is available at the end of the article
}

mixed lineage leukemia $(M L L)$ or clathrin assembly lymphoid myeloid $(C A L M)$ genes, mistargeting of DOT1L leads to transcript upregulation [10-13]. These leukemia-associated fusion proteins recruit DOT1L to target genes, with a concomitant increase in H3K79 methylation around the targeted site, upregulation of gene expression, and subsequent development of leukemia [10]. However, other studies have provided support for a repressive function of DOT1L and H3K79 methylation in mammals [14-18], and loss of Dot1 function has been shown to lead to heterochromatin defects $[16,19]$.

In yeast, $~ 90 \%$ of H3K79 is methylated by Dot1 [2]. Methylated H3K79 is mainly found in euchromatin, and absent from heterochromatic regions such as telomeres and the silent mating-type loci $[2,3,6]$. Loss of Dot1 activity leads to relocalization of Sir2, 3 and 4, the proteins responsible for heterochromatin-mediated gene silencing [2,7,20-28]. In addition, deletion of Dot 1 affects histone hypoacetylation and the ordered nucleosome positioning

\section{C) Biomed Central}


pattern found in repressive chromatin at yeast telomeres $[7,29]$. These observations suggest that H3K79 methylation prevents non-specific interactions of the Sir proteins with euchromatic nucleosomes, thus promoting Sir protein accumulation in heterochromatic regions $[20,22]$. The Sir proteins in turn prevent methylation of H3K79 by Dot1 by multiple mechanisms $[26,27,30,31]$.

The idea that H3K79 may act as an anti-binding signal is supported by the observation that binding of Sir3 to chromatin is negatively affected by methylation of H3K79 $[2,7,25,27,32-36]$, and that the presence of Dot 1 delays the re-establishment of Sir3-mediated silencing of a previously derepressed (and presumably H3K79 methylated) locus $[34,36]$. Although Dot1 affects Sir protein targeting and silencing of reporter genes, loss of Dot1 in otherwise unperturbed cells has minor effects on overall gene expression $([37,38]$ and our unpublished gene expression profiling results). However, disruption of Dot1 in combination with the disruption of additional silencing pathways results in more pronounced silencing defects in reporter genes $[24,25,39]$ and in the native silent mating-type locus $H M L \boldsymbol{\alpha}[25,34,40]$, indicating that the role of Dot1 in gene silencing is masked by redundant pathways [24].

The direct and indirect effects of Dot 1 on chromatin organization and gene regulation $[20,24,41]$ and the redundancy of Dot 1 with other pathways of silencing has made it difficult to elucidate how Dot1 affects chromatin structure and function. In this study, we determined the direct effects of Dot1 and H3K79 methylation by targeting Dot 1 to defined places in the yeast genome. Although such targeting can be considered as creating an artificial site of action, this approach has been used previously to identify activities associated directly with the targeted protein and to clarify which of these activities are lost by mutant forms. This approach has been crucial for studying histone modifiers, and provided the first line of evidence that Set2, a histone methyltransferase associated with transcription, has repressive effects on chromatin [42]. Although Dot1 did not act as a transcriptional activator, it antagonized gene silencing, and could do this from a distance. In our search for the underlying mechanism, we identified a methylationdependent mechanism that affected Sir protein targeting and a methylation-independent mechanism that involved chromatin relocalization and the histone acetyltransferase Gcn5. Our findings show that Dot1 bound to chromatin can positively affect gene expression in a genomic region, partly by inducing chromatin rearrangements over a considerable distance.

\section{Results}

\section{Dot1 is a derepressor}

The effect of local Dot1 binding and activity on gene expression was investigated by fusing Saccharomyces cerevisiae Dot1 to the Escherichia coli LexA protein and targeting it to LexA operators (LexO), which were engineered into euchromatic and heterochromatic regions of the yeast genome (Figure 1A). In contrast to the known transcriptional activator domain of Adr1, Dot1 and LexA alone did not activate transcription of a promoterless euchromatic HIS3 gene (Figure 1B). Therefore, Dot1 did not act as a transcriptional activator.

Next, Dot1 was targeted to heterochromatin, a place where Dot1 is normally not bound [6,7]. In yeast, heterochromatin initiates at silencers of the silent matingtype loci $H M L \alpha$ and $H M R$ a, and at the telomeric repeats, and can subsequently spread along the chromosome [20] in a discontinuous manner [43]. A telomeric $U R A 3$ gene was used to report changes in chromatin structure by a growth assay [44], allowing rapid screening for chromatin alterations. To examine whether Dot1 can block the spread of heterochromatin as a barrier, a LexA-Dot1 fusion protein was expressed in a strain with LexA operators in between a URA3 reporter and the telomeric repeats (Figure 1A). In strains expressing LexA alone or in strains lacking LexA operators, silencing of URA3 was unaffected (Figure 1C). However, targeting of Dot1 next to the telomeric repeats disrupted silencing at telomere VIIL (Figure 1C). Thus, Dot1 acted as a barrier at telomeres, which confirms previous findings that targeted Dot1 can prevent ectopic spreading of heterochromatin at a modified $H M R$ locus [45]. Rpd3, which was recently identified as a barrier protein [46-48], also acted as a barrier (Figure 1C), whereas targeting of several control proteins did not disrupt $U R A 3$ silencing (Figure 1D).

Because the effect of Dot1 in the barrier assay was stronger than that of the known barrier protein Rpd3, we examined possible additional effects of Dot1 in a socalled 'desilencing' assay. For this purpose, LexA operators were introduced at the centromeric (distal) side of the telomeric URA3 reporter (Figure 1A). Dot1 targeted to the distal LexA operators disrupted silencing, whereas targeted Rpd3 had no or small effects (Figure 1C). Proteins that antagonize local heterochromatin formation from a distance, but do not act as transcriptional activators of non-silenced genes are also referred to as desilencing proteins [49]. Our results show that Dot1 counteracted URA3 silencing both in a barrier and in a desilencing assay. We do not know whether barrierforming and desilencing functions of Dot1 stem from the same activity. Based on these findings, we henceforth refer to Dot1 as a derepressor.

To further investigate the derepressor activity of Dot1 and to exclude possible telomere-looping effects [50], Dot1 was targeted to a mating-type locus internal to the chromosome, $H M L \alpha$, in which the I-silencer element was inverted to allow spreading of the Sir complex to 


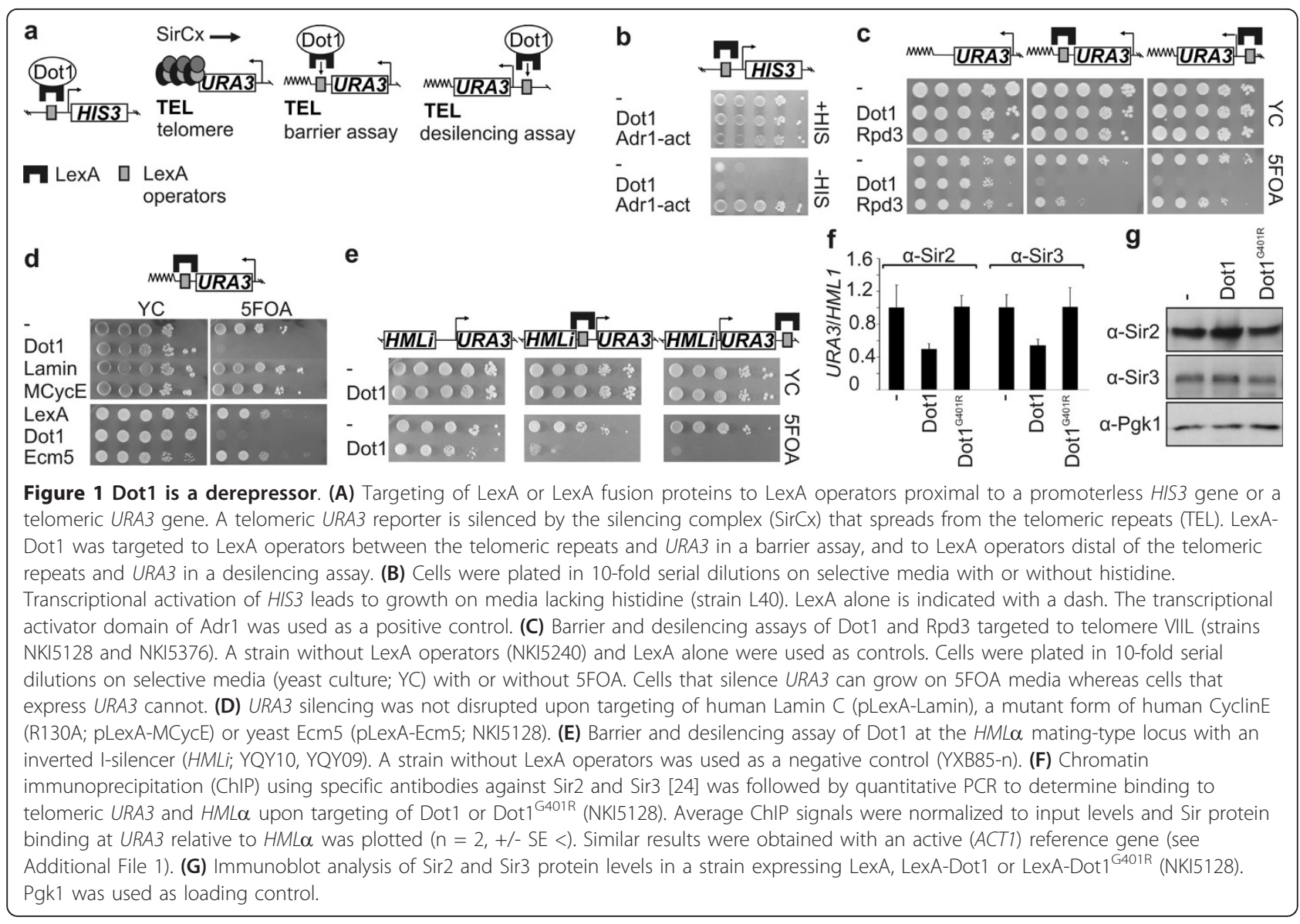

the neighboring URA3 reporter (Figure 1E) [51]. In addition, at this non-telomeric native locus, LexA-Dot1 disrupted silencing both in a barrier and a desilencing assay and, importantly, did not affect URA3 silencing in a strain without LexA operators (Figure 1E). Because the distal LexA operators and the URA3 promoter are $1.7 \mathrm{~kb}$ apart from each other, Dot1 displayed derepressor activity from a distance (Figure $1 \mathrm{E}$ ). The changes that we observed in the quantitative growth assays (and URA3 expression by reverse transcriptase quantitative (RT-q)PCR, see below) indicated that changes had occurred in the silent chromatin domain around the URA3 reporter gene.

We next investigated the mechanisms by which bound Dot1 can affect a silenced domain. Chromatin immunoprecipitation (ChIP) analysis showed that upon Dot1 targeting, Sir2 and Sir3 protein binding to telomeric URA3 was reduced by two to three times (Figure 1F; see Additional file 1) whereas global Sir2 and Sir3 expression was unaltered (Figure 1G). Therefore, at least part of the loss of silencing mediated by Dot1 seems to originate from a decrease in Sir protein binding. Targeting of a catalytically inactive Dot $1^{\mathrm{G} 401 \mathrm{R}}$ protein [2] did not affect Sir protein binding (Figure 1F). We conclude that
Dot1-mediated methylation directly affects Sir mediated chromatin and silencing from a distance, by antagonizing Sir complex binding.

\section{Dot1 displays a methyltransferase-dependent and -independent derepressor activity}

To further determine the mechanism of chromatin derepression, deletion mutants of Dot1 were generated (Figure 2A). The N-terminal domain (Dot $1^{1-237}$ ) has been implicated in chromatin binding [52]. The C-terminal domain (Dot $1^{172-582}$ ) harbors the catalytic activity and the acidic patch that binds to the basic patch on the tail of histone H4 [26,27,52]. LexA-Dot1 fusion proteins with an intact catalytic domain restored global H3K79 methylation, whereas inactive Dot1 fusions did not complement the dot1 $\Delta$ (Figure 2B).

Unexpectedly, although targeting of the catalytically inactive Dot ${ }^{\text {G401R }}$ did not alter Sir protein binding at the telomere (Figure 1F), Dot1 ${ }^{\mathrm{G} 401 \mathrm{R}}$ did show derepressor activity (Figure $2 \mathrm{CD}$ ). This effect was not due to protein overexpression alone, but acted in cis, because Dot ${ }^{\text {G401R }}$ did not affect silencing of a reporter lacking adjacent LexA operators (Figure 2D). To exclude the possibility that the Dot $1^{\mathrm{G} 401 \mathrm{R}}$ protein formed a heterodimer with 


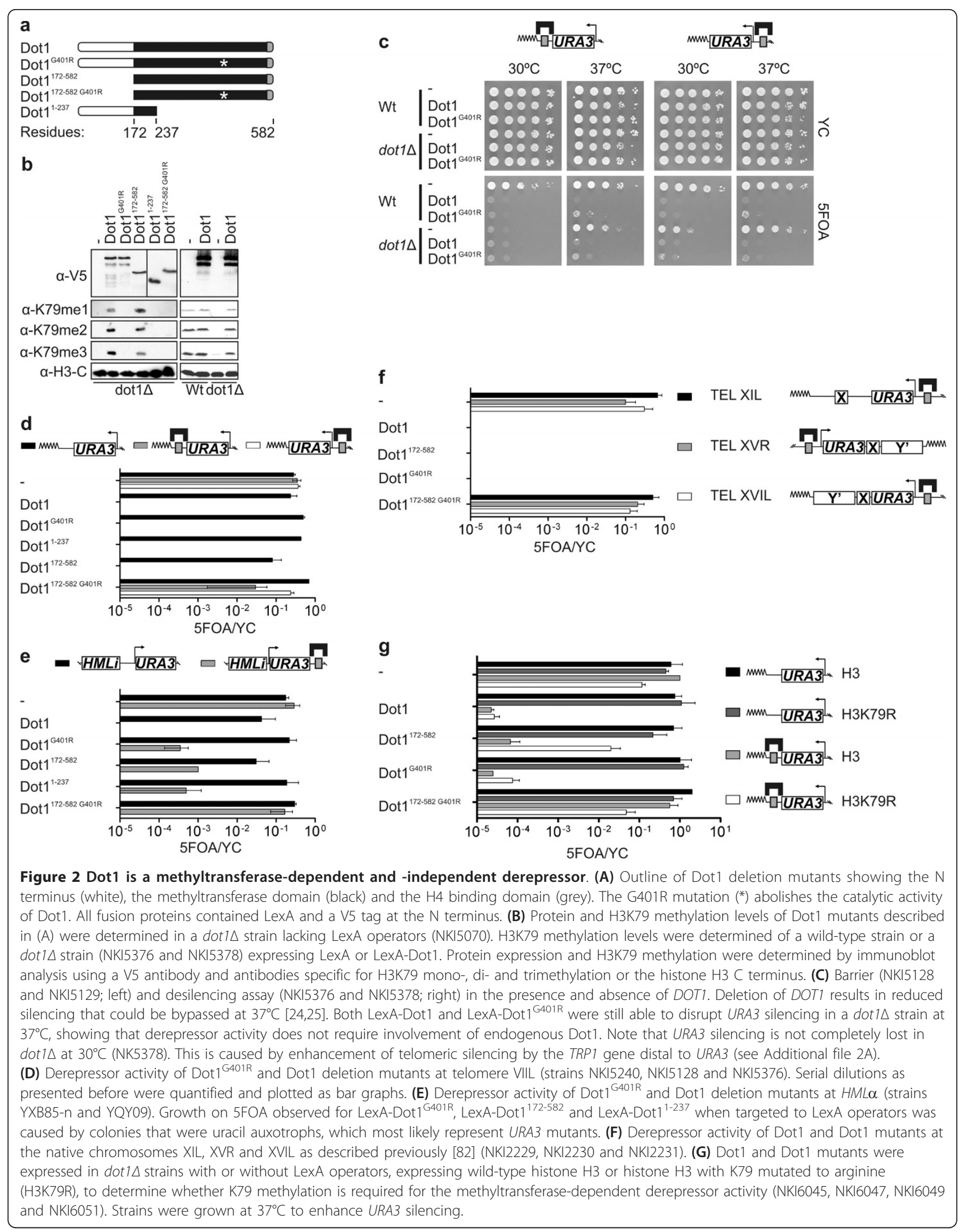


the catalytically active endogenous Dot1, we also targeted $\operatorname{Dot} 1^{\mathrm{G} 401 \mathrm{R}}$ in a $\operatorname{dot} 1 \Delta$ strain. Because deletion of DOT1 results in reduced silencing, the barrier and desilencing assays were performed at 30 and $37^{\circ} \mathrm{C}$, because high temperature enhances silencing and bypasses the need for endogenous Dot1 to silence URA3 [24,25]. Both LexADot1 and LexA-Dot $1^{\mathrm{G} 401 \mathrm{R}}$ were still able to disrupt $U R A 3$ silencing in a $\operatorname{dot} 1 \Delta$ strain at $37^{\circ} \mathrm{C}$, showing that derepressor activity does not require involvement of endogenous Dot1 (Figure 2C).

To map the derepressor domain, we analyzed the Dot1 deletion mutants. Interestingly, both the $\mathrm{N}$ terminal domain (Dot $1^{1-237}$ ) and the methyltransferase domain (Dot $1^{172-582}$ ) functioned as derepressors in both the barrier assay and the desilencing assay at telomeres and the HML $\alpha$ locus (Figure 2D-E). However, a catalytically inactive methyltransferase domain (Dot $1^{172-582}$ G401R) did not disrupt silencing (Figure 2D-E). Different native telomeres and truncated telomeres can show different silencing properties, Sir protein binding, and nucleosome positioning $[29,53,54]$. To test whether the derepressor activity of Dot1 is a general property or is restricted to the truncated telomere used here, LexA operators and the URA3 gene were introduced at three different native chromosome ends. Dot1 derepression activity was very similar at truncated telomeres and at native telomeres with or without a subtelomeric ' $\mathrm{Y}$ ' element (Figure 2F).

The only known substrate of Dot1 is histone H3K79. To verify whether the methyltransferase-dependent pathway was mediated by methylation of H3K79, we replaced histone $\mathrm{H} 3$ by a H3K79R mutant and grew strains at $37^{\circ} \mathrm{C}$ to partially suppress the URA3 silencing defect in this mutant (Figure 2G) [55]. Targeting of LexA-Dot $1^{172-582}$ resulted in derepressor activity in the presence of histone $\mathrm{H} 3$ but not in the presence of H3K79R (Figure 2G). Together, our findings show that Dot1 harbors two redundant derepressor mechanisms: one methyltransferase-independent mechanism mediated by the $\mathrm{N}$ terminus, and one mechanism mediated by its methyltransferase activity towards H3K79.

\section{Gcn5 is required for the methyltransferase-independent derepression by Dot1}

To further investigate the mechanisms of methylationdependent and -independent derepression by Dot1, we examined the role of Gcn5. This histone acetyltransferase also displayed derepressor activity (Figure 3A), as has been reported previously $[46,49,56-58]$. To test whether Gcn 5 and Dot1 are functionally related, their derepression activities were measured in strains lacking either endogenous Dot1 or Gcn5. Derepression by Gcn5 did not require Dot1 (Figure 3A). However, methyltransferase-independent derepression by Dot $1^{\mathrm{G} 401 \mathrm{R}}$ and
Dot $1^{1-237}$ was partially compromised in strains lacking Gcn5 (Figure 3A). Furthermore, LexA-Dot $1^{\text {G401R }}$ did not increase URA3 mRNA levels in gcn $5 \Delta$ cells, whereas catalytically active Dot1 proteins still showed strong derepression (Figure 3B). This confirms the anti-silencing character of H3K79 methylation. Together, our results show that the methyltransferase-independent derepressor activity mediated by the $\mathrm{N}$-terminal domain of Dot1 requires the presence of Gcn5. The role of Gcn 5 is most probably mediated by its catalytic activity (see Additional file 2B), but Rsc4, a substrate of Gcn5 [59], was not required (see Additional file 2C). We found that loss of Gcn5 did not affect normal activation of URA3 (Figure $3 \mathrm{C}$ ), but did lead to reduced expression of the LexA-Dot1 fusion proteins (Figure 3D). However, in the presence of Gcn5, low expression levels of LexADot1 were sufficient for derepression, showing that the loss of Dot1-mediated derepression in the gcn $5 \Delta$ strain was not caused by reduced expression of the LexA fusion proteins (Figure 3E). Finally, analysis of several other histone modifiers associated with active chromatin showed that the role in Dot1 derepressor activity is specific for Gcn5 (see Additional file 2(D, E)). Because the loss of URA3 derepression is not complete in a gcn5 $\Delta$ strain, these experiments also indicated that another pathway is involved in depression via the $\mathrm{N}$-terminal domain of Dot1.

\section{Tethered Dot1 caused chromatin relocalization}

To gain more insight into the possible methylationindependent mechanisms through which Dot1 derepresses Sir-repressed genes, we investigated whether Dot1 binding affected anchoring of the silenced telomere to the nuclear periphery. In yeast and metazoans, heterochromatin often clusters next to the nuclear envelope [60-63]. This clustering and peripheral localization contributes to heterochromatin establishment and maintenance [64]. We monitored the localization of a native telomere in living cells by microscopy, using a strain that has telomere VIR tagged with an array of Lac operators bound by green fluorescent protein (GFP)-LacI and telomeric LexA operators (Figure 4A). In a different strain, we confirmed that targeting of Dot1 caused derepression of a proximal URA3 reporter gene at telomere VIR (Figure 4B). The GFP-LacI labeled telomere bound by LexA was predominantly perinuclear (zone 1 as scored by position relative to the nuclear periphery), whereas a telomere bound by wild-type Dot1 had a significantly different localization, being more randomly distributed in the nucleus (Figure 4CD). Therefore, the derepression by Dot1 was accompanied by loss of perinuclear localization of the heterochromatic region.

Similar to its effect on chromatin derepression (Figure 2), the methyltransferase inactive LexA-Dot $1^{\text {G401R }}$ mutant also 


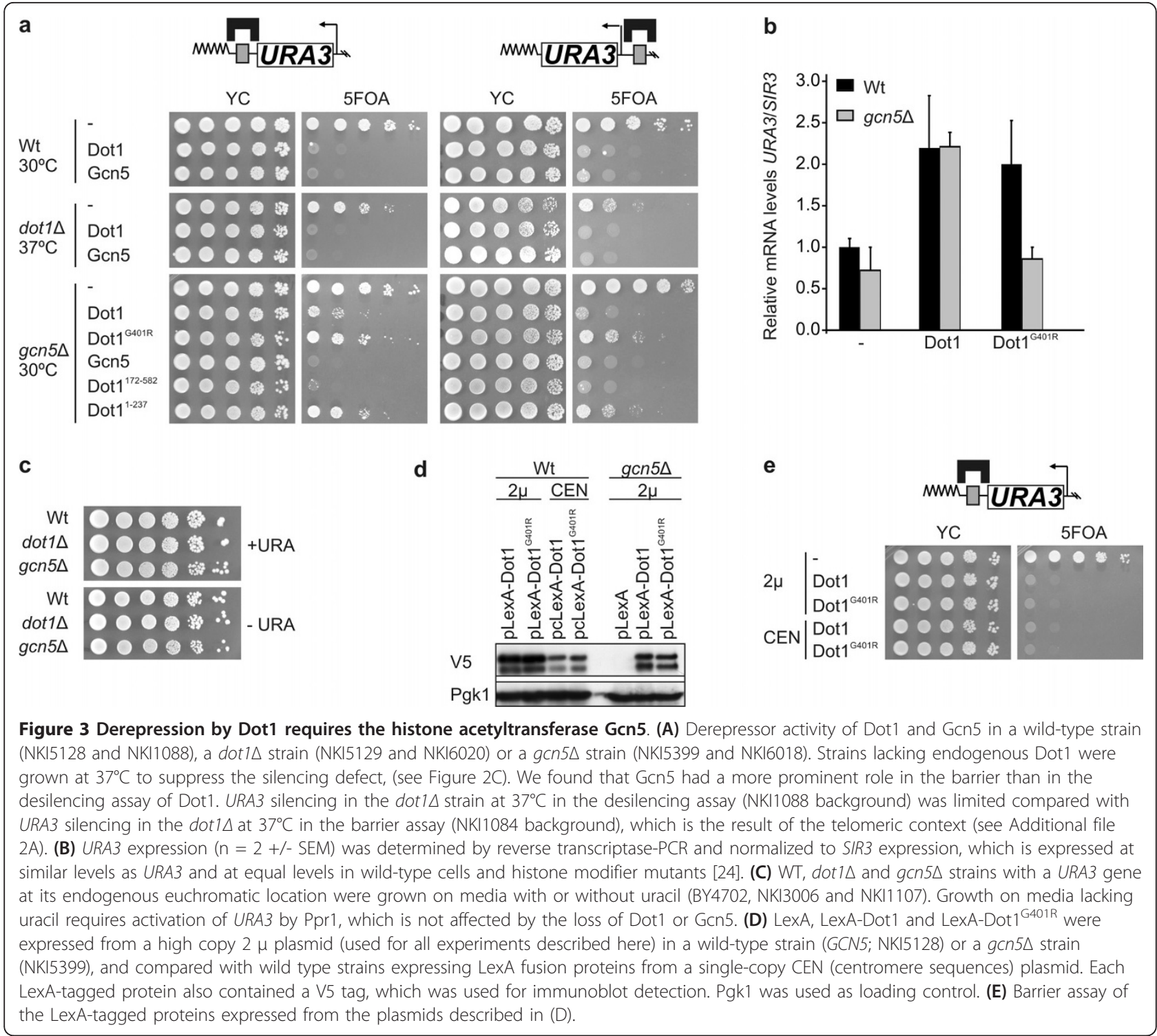

provoked the relocalization of telomere VIR away from the nuclear envelope (Figure 4CD). By contrast, binding of a catalytically active or inactive Dot1 protein lacking the $\mathrm{N}$ terminus (Dot $1^{172-582}$ and Dot1 ${ }^{172-582 ~ G 401 R}$ ) maintained significant perinuclear enrichment, similar to that observed in the presence of LexA alone (Figure 4CD). These results show that chromatin-bound Dot1 can move a telomere away from the periphery and, remarkably, that the methyltransferase activity of Dot1 is neither necessary nor sufficient for this effect. Rather, the N-terminal domain is required. Analysis of the role of Gcn5 in Dot1-mediated telomere relocalization is complicated by growth defects caused by deletion of Gcn 5 in the strain background used. However, by analyzing a different native chromosomal locus, we found that Gcn 5 could indeed promote relocalization of a chromatin domain from the nuclear periphery to the nuclear interior (see Additional file 3). These results indicate that chromatin localization away from the nuclear periphery by the $\mathrm{N}$ terminus of Dot1 may be mediated by Gen5.

\section{Discussion}

Dot1-mediated H3K79 methylation has been correlated with both increased and decreased transcription in different organisms, yet it has been difficult to distinguish global or indirect effects from local effects when interpreting $\operatorname{dot} 1 \Delta$ loss-of-function mutations. This is even more difficult in budding yeast, where the role of Dot1 in gene silencing appears to be masked by redundant pathways [24]. Nonetheless, in our study we were able to circumvent indirect effects by targeting Dot1 to defined sites in the yeast genome and comparing the 


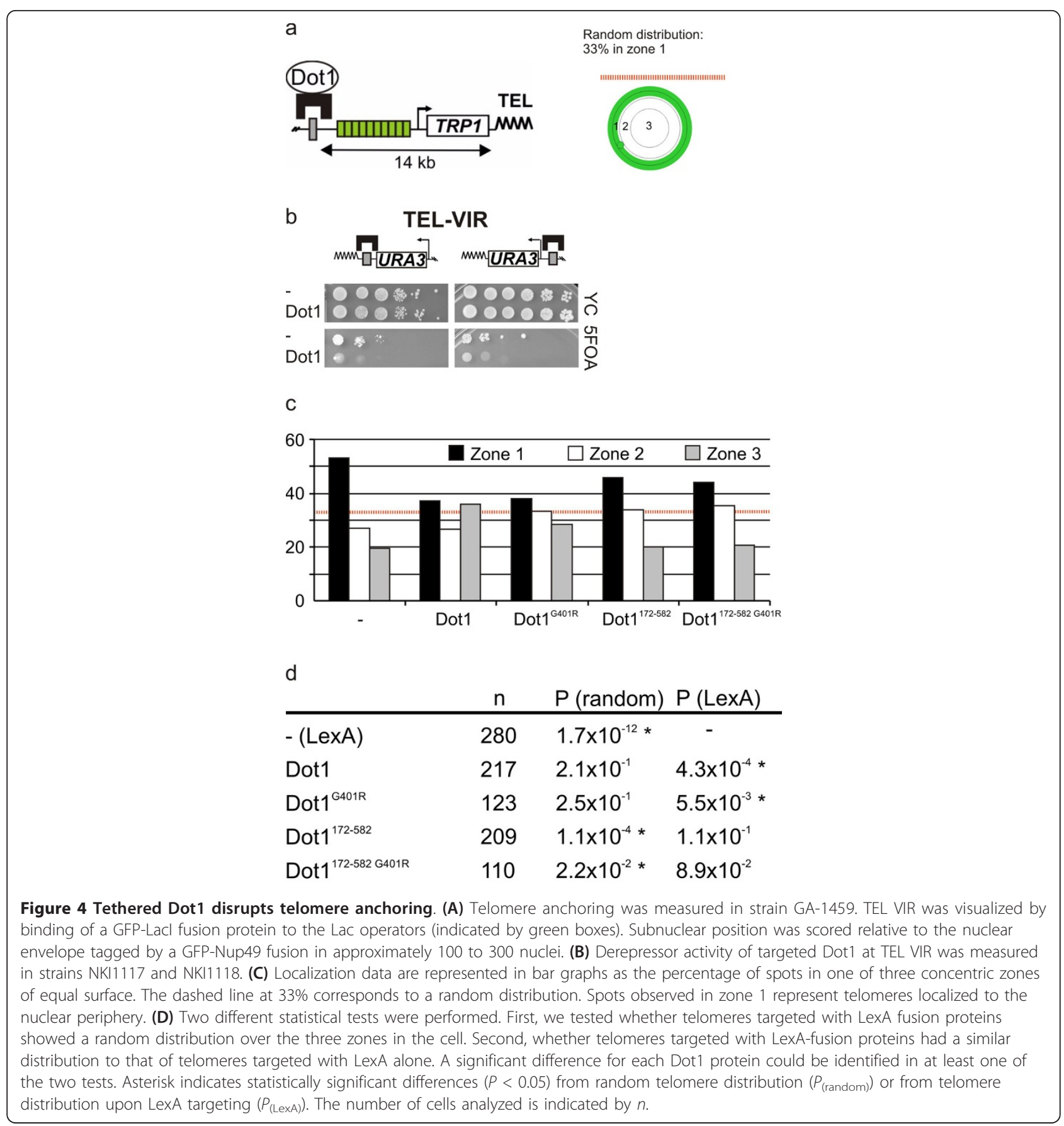

resulting phenotypes with those of a strain that lacks the target site. We found that Dot1 binding does not activate transcription in yeast, yet it antagonizes heterochromatin-mediated gene silencing. Furthermore, we found that Dot1 does not simply act as a barrier to block the spreading of heterochromatin, but actively derepresses silent chromatin from a distal position. Because Dot1 behaved similarly in both the barrier and desilencing assays, it seems likely that it acts in both assays through a common mechanism. Moreover, the ability to derepress was not restricted to yeast Dot1, because similar effects were obtained for human DOT1L when it was targeted to a yeast telomere (see Additional File 4).

Separation-of-function alleles of Dot1 show that Dot1 derepresses by two redundant mechanisms. One mechanism of derepression is mediated by H3K79 methylation, which has been shown in vitro to reduce the affinity of chromatin for Sir3 [25,27,32,33,35]. Our 
results provide direct evidence for competition between H3K79 methylation and Sir protein binding in vivo. It remains unclear, however, whether targeted Dot1 is sufficient to derepress $U R A 3$, or whether it also requires additional (non-targeted) Dot1 molecules activated by elongating RNA polymerase. It is possible that initial transcription events lead to the recruitment of the Paf1 elongation complex and subsequent ubiquitylation of $\mathrm{H} 2 \mathrm{~B}$. Both these processes would in turn stimulate the methylation of H3K79 by Dot1 [6,65-70].

The second derepression mechanism, which does not affect Sir protein binding, requires the histone $\mathrm{H} 3$ and H4 histone acetyltransferase Gcn5. How might Gcn5 assist Dot1? The genetic requirement for Gcn 5 suggests that the Dot1 $\mathrm{N}$ terminus may recruit Gcn 5 to sites at which Dot1 is bound. However, we could not detect a direct interaction between the two proteins by ChIP, yeast two-hybrid, co-immunoprecipitation or in vitro pull-down experiments with recombinant proteins. An alternative possibility is that Gcn5 triggers derepression through its global non-targeted histone acetyltransferase activity $[71,72]$. One plausible scenario is that the targeted $\mathrm{N}$ terminus of Dot1 alters local chromatin structure, allowing Gcn5 to acetylate histone tails to which it might otherwise not have access because of the local heterochromatic structure. Intriguingly, the interaction between Dot 1 and the basic patch on the histone $\mathrm{H} 4$ tail (which is also bound by Sir3 [26,27]) is not sufficient to trigger methyltransferase-independent derepression, as LexA-Dot1 ${ }^{172-580 ~ G 401 R}$, which lacks the $\mathrm{N}$ terminus but still contains the C-terminal H4-binding domain, failed to derepress (Figure 2). Indeed, we found that the $\mathrm{N}$ terminus alone is sufficient for Dot1-mediated derepression (Figure 2).

Several other factors have been identified that can act as anti-silencers, although how they affect gene expression at a distance is unclear [49]. We explored potential mechanisms through which Dot1 might derepress silencing at a distance. In yeast, transcriptional regulators typically do not function from downstream positions, but act by binding to upstream activation sequences (UAS) that are positioned within a few hundred base pairs from the transcription start site $[50,73]$. This is in contrast to gene regulation by enhancers (the UAS counterparts in mammalian cells), which can act over longer ranges and also from downstream positions [74]. Silencing in yeast is highly sensitive to local Sir factor concentration, and is therefore strongly enhanced by the recruitment of silencers and silent domains to the nuclear envelope [75], where Sir proteins accumulate in foci that colocalize with clusters of yeast telomeres. Quantitative analysis of subnuclear localization induced by Dot 1 targeting suggests that Dot 1 contributes to derepression by promoting the relocation of a domain away from the repressive environment at the nuclear periphery.

In budding yeast, the telomeres and the two silent mating-type loci, $H M L$ and $H M R$, co-localize in four to eight clusters at the nuclear periphery. Many Sir binding sites are created by the binding of Rap1 to the telomeric repeats and the anchoring of telomeres through both $\mathrm{yKu}$ and Sir4, leading to the sequestration of Sir proteins away from the rest of the genome [64,76]. Positioning a promoter or gene near the telomere (or indeed anywhere at the nuclear envelope) in a strain that has functional telomere anchoring facilitates stable gene repression, as long as the targeted reporter contains Sir nucleating elements, such as silencers or protosilencers [61,77-79]. The relocation of a region bound by Dot1 is likely to influence the subnuclear position of neighboring genes because chromatin is a contiguous compacted fiber with limited flexibility, and this would explain why tethered Dot1 functions as derepressor from a distance.

Loss of anchoring was achieved by targeting of the activity-deficient Dot ${ }^{\mathrm{G} 401 \mathrm{R}}$, suggesting that the methyltransferase-independent derepression described above depends on or correlates with relocalization (Figure 4). Interestingly, conditions that lead to telomere relocalization (targeting of Dot $1^{\mathrm{G} 401 \mathrm{R}}$ ) did not lead to detectable changes in Sir protein binding (Figure 1F). Whether targeting of a catalytically inactive Dot1 caused qualitative changes in chromatin or small quantitative changes that remained undetected by ChIP is still unknown.

Telomeric heterochromatin is anchored to the nuclear periphery by two pathways, one of which is enhanced by formation of silent chromatin, whereas the other involves the DNA-end binding complex yKu [61]. Although the local H3K79 methylation mediated by targeted Dot1 was able to disrupt Sir complex association $[27,32,33]$, it was not sufficient to cause loss of telomere anchoring (Figure 1, 2, 4). This is most likely due to a redundant anchoring pathway mediated by $\mathrm{yKu}$, which helps tether telomeres in the absence of Sir-mediated repression [80].

The distal effects of Dot1-mediated H3K79 methylation on gene silencing are in line with observations that yeast heterochromatin spreads in a discontinuous fashion [43]. The establishment of silent chromatin domains at yeast telomeres is determined by anti-silencing and relay elements $[29,54,81,82]$. Therefore, one possibility is that Dot1 bound at distal sites also disrupts the interaction between such relay elements. We found that a nourseothricin resistance (NatMX) gene cassette was also able to disrupt gene silencing from a distal position (see Additional file 2A), lending further support for the notion that distal elements can influence silencing at telomere proximal positions. 


\section{Conclusions}

Previous analyses showed that histone H3K79 methylation by Dot1 in euchromatin indirectly promotes heterochromatin formation. In this paper, we show that at a local level Dot1 can counteract heterochromatin formation by H3K79 methylation and chromatin relocalization, which is in agreement with the observed loss of silencing by very high overexpression of Dot1 [2,21, 27,83]. Together, these results suggest that Dot1 functions as complex modulator of heterochromatin organization. The relative strength of the indirect and more direct Dot1 activities, gene-specific characteristics, and the contribution of other pathways of heterochromatin formation will together fine-tune heterochromatin establishment and gene expression.

Human DOT1L also derepressed silent chromatin in yeast (see Additional file 4). If human DOT1L plays similar roles in mammals, mistargeting of DOT1L in human leukemia might antagonize gene silencing or repression, and thereby lead to higher gene expression levels. Although the catalytic activity of DOT1L has been shown to be required for leukemic transformation and maintenance of the transformed state by MLL and CALM fusion proteins in in vitro models, it is possible that DOT1L collaborates with other euchromatic modifiers such as Gcn5 to establish and maintain the altered gene expression levels in human leukemias. Identification of the molecular mechanisms of derepression by human DOT1L will be crucial for understanding the role of DOT1L in leukemias bearing MLL and CALM fusion proteins.

\section{Methods \\ Yeast strains and plasmids}

The yeast strains and plasmids used in this study are specified in the supplementary material (see Additional file 5 Additional file 6 . To obtain strains with a URA3 reporter for telomeric silencing, telomere VIIL was truncated at $\mathrm{ADH} 4$ by integration of URA3- $\mathrm{LexO}_{3}$-TEL-VIIL (three LexA binding sites; pVIIL-URA3-LexAS3-TEL [84]), URA3-LexO $\mathrm{L}_{2}$-TEL-VIIL (two LexA binding sites; pVIIL-URA3-LexAS2-TEL [84]), URA3-TEL-VIIL (pADH4UCA-IV [85]) or LexO ${ }_{10}$-URA3-TEL-VIIL (pT7 [86]) in an Y7092 background (NKI1084, NKI5070, NKI5072, NKI5128, NKI5240, NKI5376, NKI5420, NKI5422). A NatMX selection cassette was introduced by homologous recombination distal to the LexA operators in NKI5376 (NKI1088; primers ADH4tINT1KO and ADH4tINT2KO). Strain NKI1117 and NKI1118 were generated by targeting the URA3- $\mathrm{LexO}_{3}$-TEL barrier cassette from pVIIL-URA3-LexO $\mathrm{O}_{3}$-TEL or the TRP1LexO $_{10}$-URA3-TEL desilencing cassette from pT7, respectively, to telomere VIR in strain BY4733, thereby truncating the endogenous telomere. The cassettes were amplified using primers URA3_TELVIRtr_F1 and URA3_TELVIRtr_F2, respectively and URA3_TELVIRtr_R1. A genomic region of TEL VIR was amplified using primers TELVIR-3907_F and TELVIR-3463_R, and subsequently fused to the reporter cassettes by overlap PCR. Primers used to target TEL VIR are shown in the primer list. A LexO $\mathrm{L}_{5}$-URA3 desilencing cassette was targeted to native telomeres of TEL XIL (NKI2229), TEL XVIL (NKI2230) and TEL XVR (NKI2231) of strain Y7092. A LexO 5 region was amplified from plasmid pT7 using primers LUJ2 and DLU-11L-DF2 or DLU-15R/ 16L-DF2. The URA3 gene was amplified from pURA3TEL VIIL using primers LUJ1 and BDUL-11L-R1 or BDUL15R/16L-R1. The fragments were fused by overlap PCR and targeted to position P2 (11L) or P1 (15R/16L), as described previously [82]. Integrations were verified by PCR using telomere-specific primers and by sequencing of regions around the insertion site. Strains NKI1043 and NKI6041-NKI6051 were derived from UCC1369 [2]. UCC1369 was crossed with BY4727 to remove silencing reporters and hhf1-hht1 $\triangle::$ LEU2 was replaced by hhft1-hht1 $\Delta::$ HIS3 to obtain NKI6041. URA3-LexO ${ }_{3}$-TEL VIIL or URA3-TEL VIIL was targeted to telomere VIIL of NKI6041 to obtain NKI6042 or NKI6043, respectively. Subsequently, pMP9 was replaced by pMP3 (H3, NKI6045 and NKI6047) or by pFvl88 (H3K79R, NKI6047 and NKI6051) via a plasmidshuffle procedure. Strains harboring a gene-specific knockout were made using the plasmids pRS400, pFvl99 and pFvl100.

Plasmid pFvL232 was made by amplification of the $\mathrm{P}_{\mathrm{ADH} 1}$-LexA fragment from $\mathrm{pBTM} 116$ using a threestep PCR protocol (primers LexADot1V5P2 and LexAV5P3) that resulted in the introduction of a V5 tag (GKPIPNPLLGLDST). The appended NotI and SpeI sites were used to clone the fragment into pRS425. Plasmid pFvL230 was made by performing several steps. First, the full-length Dot1 open reading frame (ORF) was amplified with primers that included a 5'EcoRI site and 3' BamHI site to clone the Dot1 ORF into pBTM116 and generate pFvL23. Using a three-step PCR protocol, a V5 tag was inserted in between LexA and Dot1 to generate $\mathrm{P}_{\mathrm{ADH} 1}$-LexA-V5-Dot1 (primers LexADot1V5P2 and LexADot1V5P3), and the resulting PCR fragment was cloned in pRS425 using the appended NotI and SpeI sites. pFvL909 was generated by gap repair of pFvL230 using double-strand oligonucleotides to introduce an SV40 nuclear-localization signal (NLS) (PKKKRKV) [87] and a unique NruI site. A Dot $1^{\text {G401R }}$ mutant (pFvl908) was generated by oligo-mediated sitedirected mutagenesis on pFvL230. Deletion mutants of Dot1 (pFvl905, pFvl913, pFvl901) were made by replacing full length Dot1 in pFvL230 with PCR-amplified Dot1 deletion fragments by cloning or by inserting the 
fragments into pFvL909 by gap repair to include the SV40 NLS. Plasmid pIS001 was made by gap repair using a G401R fragment of DOT1 and plasmid pFvL901 digested with BsaBI and NheI. Plasmids pFvL914 and pFvL916 were generated by gap repair by co-transformation of the LexA-V5-Dot1 fragment from pFvL230 and pFvL908 digested with BsrGI-XbaI and pRS315 digested with $A l w$ NI and EcoRI. Deletion of the N-terminal domain disrupted a putative NLS. Although LexA has been suggested to have nuclear-localization properties [88], Dot1 mutants without an $\mathrm{N}$-terminal domain were fused to an NLS. Plasmids pFvL925 and pFvL927 were made by PCR amplification of $\mathrm{N}$-terminal fragments of human Dot1 from pCDNA3B-FLAG-hDot1L and replacement of yeast Dot1 in pFvL230 by gap repair. Plasmid pFvL921 was made by amplification of the RPD3 ORF from genomic DNA and replacement of Dot1 in pFvL230 by gap repair. Plasmid pFvl250 was made from a MORF-ECM5-HA-TAP plasmid (pYMR176) in two steps. First, the URA3 marker was replaced with a LEU2 marker by gap repair using the AatII/PvuII LEU2 fragment of pRS305. Next, the GAL1 promoter was replaced by a $1.2 \mathrm{~kb}$ fragment containing the $A D H 1$ promoter linked to LexA-V5 (from pFvL230) and an upstream hygromycin resistance (HphMX) marker (from pFvL100) was inserted. Plasmids pRS400, pFvL99 and pFvL100 were used for gene replacements by KanMX4 (kanamycin resistance), NatMX4 and HphMX4, respectively. To generate pFvL99 and pFvL100, the PacI/BsmI KanMX4 insert of pRS400 was replaced by the PacI/ BsmI insert of pAG25 or pAG32 [89], respectively. The drug-resistance cassettes were amplified using the standard pRS primers [90].

Yeast growth and silencing assays were performed as described [21]. To analyze gene expression of the URA3 reporter, strains were plated in 10-fold dilution series on media with or without 5 -fluoroorotic acid (5FOA), which is toxic and inhibits growth when URA3 is expressed [44]. Media for growth assays of strains expressing a LexA-fusion protein lack leucine to select for presence of the plasmid. Growth assays to analyze HIS3 activation were performed on media lacking leucine and histidine.

\section{Protein analysis}

Cell extracts were made as described previously using glass beads and SUMEB buffer containing phenylmethylsulfonyl fluoride $(1 \mathrm{mmol} / \mathrm{l})$, benzamidine $(5 \mathrm{mmol} / \mathrm{l})$, pepstatin $(1.5 \mathrm{mmol} / \mathrm{l})$, leupeptin $(2 \mathrm{mmol} / \mathrm{l})$ and dithiothreitol $(1 \mu \mathrm{mol} / \mathrm{l})$ [91]. Primary antibody incubations were performed in Tris-buffered saline-Tween with $2 \%$ dry milk. Primary antibodies used for immunodetections were V5 antibody (R960-25; Invitrogen, Breda, The NetherlandsH3, H3K79me1, H3K79me2 and H3K79me3
[21], PGK1 (A-6457; Molecular Probes, Breda, The Netherlands).

\section{Chromatin Immunoprecipitation}

ChIP was performed as described previously [2]. Chromatin was sheared for 6 minutes with 30 second intervals, using a Bioruptor (Diagenode). ChIP analyses were performed with anti-H3 [21], anti-Sir2 (yN-19; SantaCruz) and anti-Sir3 [2] antibodies coupled to magnetic beads (Dynabeads; Invitrogen). ChIP DNA was quantified by real-time qPCR analysis using a commercial master mix and thermal cycler $\left(\mathrm{SYBR}^{\circledR}\right.$ Green PCR Master Mix and ABI PRISM 7500; Applied Biosystems). A standard curve was made from one of the input samples, which was then used to calculate the relative expression of the other samples using 7500 Fast System software. For primers, see Additional file 7.

\section{mRNA quantification}

RNA was extracted (RNeasy Kit; Qiagen), and cDNA made by using reverse transcriptase (Super-Script II; Invitrogen). RT-PCR fragments were separated on gels and quantified using the TINA 2.09 software (Raytest). Primers are described in Additional file 7. Gene expression profiling of a $\operatorname{dot} 1 \triangle:: K a n M X$ strain derived from BY4742 was performed as described previously [92].

\section{Live imaging of telomere localization}

For live imaging, yeast strain GA-1459 was used, which has TEL VIR tagged with four LexA operators (LexO) and an array of Lac operators ( $\mathrm{LaCO}$ ), and expresses GFP-LacI to visualize the LacO and GFP-Nup49 to tag the nuclear periphery [93]. Cultures of GA-1459 containing LexA plasmids were grown in synthetic medium lacking leucine to a concentration of 0.2-0.4 $\times 10^{7}$ cells $/ \mathrm{ml}$. For subnuclear position analysis, living cells were imaged at $30^{\circ} \mathrm{C}$ on agarose patches containing synthetic complete medium $+4 \%$ glucose as described [93]. Stacks of 21 images of $0.2 \mu \mathrm{m}$ step size were captured on a wide field microscope (Metamorph-driven IX70; Olympus) equipped with a camera (Coolsnap HQ; Roper Scientific Photometrics). The radial position of tagged TEL VIR was assigned to one of three concentric zones of equal surface in the focal plane bearing the brightest GFP-LacI focus as described [93]. Nuclei in which the focus was detected in the three top or bottom focal planes were excluded from the analysis. A $\chi^{2}$ test was used to determine if the measured frequency of TEL VIR position in zone 1 differed from a random distribution using a $95 \%$ confidence limit. A proportional analysis was used to measure confidence values between two strains. For each strain, nuclei from four to five independent cultures were combined. 


\section{Additional material}

Additional file 1: Chromatin immunoprecipitation of Sir2 and Sir3 normalized to an actively transcribed gene. Chromatin

immunoprecipitation (ChIP) using specific antibodies against Sir2 and Sir3 [24] was followed by quantitative PCR to determine binding to telomeric URA3 and ACT1 upon targeting of Dot1 or Dot ${ }^{\text {G401R }}$ (NKI5128). Average ChIP signals were normalized to input levels and Sir protein binding at URA3 relative to Sir protein binding at the actively transcribed ACT1 locus was plotted ( $n=2,+/$ - SEM).

\section{Additional file 2: Characterization of the role of Gon5 in}

derepression by Dot1. (A) URA3 silencing was determined in strains with a different genomic context at telomere VIIL. The indicated numbers refer to the distance $(\mathrm{kb})$ from the URA3 promoter. Strains from top to bottom are NKI1084, NKI1087, NKI5376 and NKI1088. Gene cassettes inserted on the centromeric side of URA3 could positively and negatively affect URA3 silencing, supporting our observations that silencing is not only determined by linear spreading from the telomeric repeats but can also be influenced by distal sequences. This may help to explain the observed differences in silencing between native telomeres [82]. (B) Gcn5 or a catalytic inactive mutant ( $\left.\mathrm{G} c n 5^{\mathrm{F} 221 \mathrm{~A}}\right)$ [94] were expressed together with LexA, LexA-Dot1 or LexA-Dot1 ${ }^{\mathrm{G} 401 \mathrm{R}}$ in a strain lacking endogenous Gcn5 (NKI2214). Under these conditions, expression of $\mathrm{Gcn} 5^{\mathrm{F} 221 \mathrm{~A}}$ (and to a lesser extent the empty vector) resulted in slow growth and reduced silencing (for example, see LexA alone). The extremely small colonies on 5FOA plates precluded a reliable analysis of the silencing phenotype. Despite the poor growth conditions of the Gen5 $5^{\text {F221A }}$ strain, the LexA-Dot $1^{\text {G401R }}$ protein consistently allowed colony growth on 5-fluoroorotic acid media, whereas no colonies were observed in the much better-growing GCN5 strain. This result indicates that catalytic activity of Gcn5 may be required for derepressor activity of LexA-Dot1 and LexA-Dot1 ${ }^{\mathrm{G} 401 \mathrm{R}}$. (C) Rsc4 is acetylated by Gen5 and mediates some of the functions of Gcn5 [59]. A barrier assay with LexADot1 and LexA-Dot1 ${ }^{\mathrm{G} 401 \mathrm{R}}$ revealed that the Dot1 derepressor activity was independent of Rsc4 acetylation at K25. (D) Barrier assays in strains lacking the indicated gene. These strains were obtained by crossing the strain containing the tagged telomere with strains of the yeast knockout collection. None of the genes analyzed affected Dot1 derepressor activity. The gcn5 $\Delta$ strain was used as a control. (E) Barrier assay in strains in which the indicated genes were deleted by homologous recombination. Because set $1 \Delta$ showed a silencing defect, derepression was examined at $37^{\circ} \mathrm{C}$

Additional file 3: Gcn5 is required for relocalization of ARS1413 to the nuclear interior by Gcn4. Subnuclear positioning of ARS1413 was monitored in a strain harboring Lac operators next to the origin of replication. The locus was visualized by binding of a GFP-Lacl fusion protein to the Lac operators (indicated by green boxes). Subnuclear position was scored relative to the nuclear envelope visualized by a GFPNup49 fusion in G1 and S phase cells. Localization data are represented in bar graphs as the percentage of spots in one of three concentric zones of equal surface. The dashed line at 33\% corresponds to a random distribution. Spots observed in zone 1 represent ARS1413 localized to the nuclear periphery. The number of cells analyzed is indicated by $n$. $P$ values indicate whether the distributions over the three zones in the cell were significantly different from a random distribution (see Figure 4). ARS1413 showed a non-random distribution with bias towards the nuclear periphery. Insertion of binding sites for the transcriptional activator Gcn4 [95], which is known to recruit and require Gcn5 for its function [96,97], changed the localization of ARS1413 to a more random distribution. Deletion of Gcn5 suppressed the change in localization caused by Gcn4 binding. These results suggest that recruitment of Gcn5 can stimulate the localization of a chromatin domain away from the nuclear periphery. This is in line with the observed role of Gcn5 in derepression of a silenced telomere by the $\mathrm{N}$ terminus of Dot1 (Figure 2), which is also involved in relocalization of a tagged telomere away from the nuclear periphery (Figure 4).

Additional file 4: Human Dot1 has derepressor activity in yeast. (A) Human DOT1L (1537 residues) consists of a N-terminal methyltransferase domain homologous to the yeast methyltransferase domain $\left(\right.$ hDot $\left.1^{1-340}\right)$, followed by a lysine-rich region that shows weak homology to the N-terminal domain of yDot1 (hDot1 ${ }^{318-430}$ ), and a large domain of unknown function $[52,98]$. The catalytically active N-terminal part of human DOT1L (LexA-hDot ${ }^{1-340}$ ), a part containing only the lysine-rich region (LexA-hDot1 ${ }^{318-430}$ ) and the combination of both domains (LexA-hDot1 ${ }^{1-430}$ ) were fused to LexA-V5. (B) LexA-tagged hDOT1L proteins were expressed in yeast cells. Protein expression and histone methylation was analyzed as described in Figure 2. LexA fusion proteins of hDot $1^{1-340}$ and hDot $1^{1-430}$ showed mono- and dimethylation of $\mathrm{H} 3 \mathrm{~K} 79$ but no detectable trimethylation in yeast. (C) Barrier and desilencing assays (NKI5128 and NKI5376) of LexA-tagged hDOT1L proteins. In strains harboring LexA operators within telomeric heterochromatin, the catalytically active hDOT1L protein showed robust derepressor activity. Although the hDOT1L domain with weak homology to the yeast $\mathrm{N}$-terminal domain was required for the full derepressor activity of hDOT1L (compare hDot $1^{1-430}$ with Dot $1^{1-340}$ ), the hDot1 ${ }^{318-430}$ domain alone showed no detectable derepressor activity. These results indicated that the lysine-rich region of human DOT1L is not sufficient for, but contributes to, the derepressor activity in yeast of the conserved methyltransferase domain of DOT1L. Because yeast cells lacking endogenous Dot1 but expressing the hDOT1L methyltransferase domain show no detectable trimethylation, these results also show that efficient trimethylation of H3K79 is not required for derepression. This is in line with previous observations, which showed that multiple levels of H3K79 methylation (that is, mono-, di- and trimethylation) can affect Sir3 binding and silencing $[21,27]$.

Additional file 5: List of yeast strains used in this study. Additional file 6: List of plasmids used in this study. Additional file 7: Primer list.

\section{Acknowledgements}

We thank M. Krijnen for help with construction of deletion mutants; F. Neumann for help with the localization studies; D. Gottschling, X. Bi, B. Cairns, C. Boone, H.T.M. Timmers, Y. Zhang, S. Fields, J. Singer and B. Eisenman for plasmids and strains; M. Hauptmann for help with statistics; and members of the van Leeuwen lab for helpful discussions and critical reading of the manuscript. This work was supported by the EU 6th framework program (NOE 'The Epigenome' LSHG-CT-2004-503433), by The Netherlands Organisation for Scientific Research (NWO), the Netherlands Genomics Initiative, and a NWO talent stipendium (021.002.035) to TLL. The Gasser laboratory is supported by the Novartis Research Foundation and a fellowship from the Human Frontiers Science Program to BLP.

\section{Author details}

'Division of Gene Regulation, Netherlands Cancer Institute, Netherlands Proteomics Centre, Plesmanlaan 121, 1066CX Amsterdam, The Netherlands. ${ }^{2}$ Friedrich Miescher Institute for Biomedical Research, Maulbeerstrasse 66, 4058 Basel, Switzerland. ${ }^{3}$ Department Molecular Cancer Research, University Medical Center Utrecht, Universiteitsweg 100, 3584 CG Utrecht, The Netherlands.

\section{Authors' contributions}

IJES, AWF and TVW carried out the constructions of plasmids and strains and performed silencing assays, western blots and RT-PCR. KV and FF carried out ChIP analyses. BLP performed nuclear localization experiments. TLL performed gene expression profiling and data analysis. IJES, AWF and FVL conceived of the study. SMG and FCPH analyzed the localization and expression data and contributed to the final manuscript. IJES, SMG and FVL wrote the paper. All authors read and approved the final manuscript.

\section{Competing interests}

The authors declare that they have no competing interests.

Received: 12 October 2010 Accepted: 3 February 2011

Published: 3 February 2011 


\section{References}

1. Bhaumik SR, Smith E, Shilatifard A: Covalent modifications of histones during development and disease pathogenesis. Nat Struct Mol Biol 2007 14:1008-1016.

2. van Leeuwen F, Gafken PR, Gottschling DE: Dot1p modulates silencing in yeast by methylation of the nucleosome core. Cell 2002, 109:745-756.

3. Schulze JM, Jackson J, Nakanishi S, Gardner JM, Hentrich T, Haug J, Johnston M, Jaspersen SL, Kobor MS, Shilatifard A: Linking cell cycle to histone modifications: SBF and $\mathrm{H} 2 \mathrm{~B}$ monoubiquitination machinery and cell-cycle regulation of H3K79 dimethylation. Mol Cell 2009, 35:626-641.

4. Schubeler D, MacAlpine DM, Scalzo D, Wirbelauer C, Kooperberg C, van Leeuwen F, Gottschling DE, O'Neill LP, Turner BM, Delrow J, et al: The histone modification pattern of active genes revealed through genomewide chromatin analysis of a higher eukaryote. Genes Dev 2004 18:1263-1271.

5. Steger D, Lefterova M, Ying L, Stonestrom A, Schupp M, Zhuo D, Vakoc A Kim J, Chen J, Lazar M, et al: DOT1L/KMT4 recruitment and H3K79 methylation are ubiquitously coupled with gene transcription in mammalian cells. Mol Cell Biol 2008, 28:2825-2839.

6. Shahbazian MD, Zhang K, Grunstein M: Histone H2B ubiquitylation controls processive methylation but not monomethylation by Dot1 and Set1. Mol Cell 2005, 19:271-277.

7. $\mathrm{Ng} \mathrm{HH}$, Ciccone D, Morshead K, Oettinger M, Struhl K: Lysine-79 of histone $\mathrm{H} 3$ is hypomethylated at silenced loci in yeast and mammalian cells: A potential mechanism for position-effect variegation. Proc Natl Acad SC USA 2003, 100:1820-1825

8. Mahmoudi T, Boj SF, Hatzis P, Li VS, Taouatas N, Vries RG, Teunissen $H$ Begthel H, Korving J, Mohammed S, et al: The leukemia-associated Mllt10/ Af10-Dot1l Are Tcf4/beta-catenin coactivators essential for intestinal homeostasis. PLoS Biol 2010, 8:e1000539.

9. Jacinto FV, Ballestar E, Esteller M: Impaired recruitment of the histone methyltransferase DOT1L contributes to the incomplete reactivation of tumor suppressor genes upon DNA demethylation. Oncogene 2009, 28:4212-4224.

10. Krivtsov AV, Armstrong SA: MLL translocations, histone modifications and leukaemia stem-cell development. Nat Rev Cancer 2007, 7:823-833.

11. Krivtsov AV, Feng Z, Lemieux ME, Faber J, Vempati S, Sinha AU, Xia X, Jesneck J, Bracken AP, Silverman LB, et al: H3K79 methylation profiles define murine and human MLL-AF4 leukemias. Cancer Cell 2008 14:355-368.

12. Guenther M, Lawton L, Rozovskaia T, Frampton $G$, Levine $S$, Volkert $T$, Croce C, Nakamura T, Canaani E, Young R: Aberrant chromatin at genes encoding stem cell regulators in human mixed-lineage leukemia. Genes Dev 2008, 22:3403-3408.

13. Okada $Y$, Jiang $Q$, Lemieux $M$, Jeannotte $L$, Su L, Zhang $Y$ : Leukaemic transformation by CALM-AF10 involves upregulation of Hoxa5 by hDOT1L. Nat Cell Biol 2006, 8:1017-1024.

14. Zhang D, Li S, Cruz P, Kone B: Sirtuin 1 functionally and physically interacts with disruptor of telomeric silencing- 1 to regulate á-ENaC transcription in collecting duct. J Biol Chem 2009, 284:20917-20926.

15. Shanower G, Muller M, Blanton J, Honti V, Gyurkovics H, Schedl P: Characterization of the grappa gene, the Drosophila histone H3 lysine 79 methyltransferase. Genetics 2005, 169:173-184.

16. Gazin C, Wajapeyee N, Gobeil S, Virbasius CM, Green MR: An elaborate pathway required for Ras-mediated epigenetic silencing. Nature 2007, 449:1073-1077.

17. Singh $P$, Han L, Rivas GE, Lee DH, Nicholson TB, Larson GP, Chen T, Szabo PE: Allele-specific H3K79 Di- versus trimethylation distinguishes opposite parental alleles at imprinted regions. Mol Cell Biol 2010, 30:2693-2707.

18. Figueiredo $\mathrm{L}$, Janzen $\mathrm{C}$, Cross $\mathrm{G}$ : $\mathrm{A}$ histone methyltransferase modulates antigenic variation in African trypanosomes. PLOS Biol 2008, 6:e161.

19. Jones B, Su H, Bhat A, Lei H, Bajko J, Hevi S, Baltus GA, Kadam S, Zhai H, Valdez R, et al: The histone H3K79 methyltransferase Dot1L is essential for mammalian development and heterochromatin structure. PLOS Genet 2008, 4:e1000190.

20. Rusche $L N$, Kirchmaier $A L$, Rine J: The establishment, inheritance, and function of silenced chromatin in Saccharomyces cerevisiae. Annu Rev Biochem 2003, 72:481-516.

21. Frederiks F, Tzouros $M$, Oudgenoeg $G$, van Welsem $T$, Fornerod $M$ Krijgsveld J, van Leeuwen F: Nonprocessive methylation by Dot1 leads to functional redundancy of histone H3K79 methylation states. Nat Struct Mol Biol 2008, 15:550-557.

22. Norris A, Boeke JD: Silent information regulator 3: the Goldilocks of the silencing complex. Genes Dev 2010, 24:115-122.

23. San Segundo PA, Roeder GS: Role for the silencing protein Dot1 in meiotic checkpoint control. Mol Biol Cell 2000, 11:3601-3615.

24. Verzijlbergen KF, Faber AW, Stulemeijer IJE, van Leeuwen F: Multiple histone modifications in euchromatin promote heterochromatin formation by redundant mechanisms in Saccharomyces cerevisiae. BMC Molecular Biology 2009, 10.

25. van Welsem T, Frederiks F, Verzijlbergen KF, Faber AW, Nelson Z, Egan DA Gottschling DE, van Leeuwen F: Synthetic lethal screens in yeast identify gene silencing pathways and implicate the acetylated amino terminus of Sir3 in recognition of the nucleosome core. Mol Cell Biol 2008, 28:3861-3872.

26. Fingerman I, Li H, Briggs S: A charge-based interaction between histone $\mathrm{H} 4$ and Dot1 is required for $\mathrm{H} 3 \mathrm{~K} 79$ methylation and telomere silencing: identification of a new trans-histone pathway. Genes Dev 2007, 21:2018-2029.

27. Altaf M, Utley RT, Lacoste N, Tan S, Briggs SD, Cote J: Interplay of chromatin modifiers on a short basic patch of histone $\mathrm{H} 4$ tail defines the boundary of telomeric heterochromatin. Mol Cell 2007, 28:1002-1014.

28. Wan Y, Chiang JH, Lin CH, Arens CE, Saleem RA, Smith JJ, Aitchison JD: Histone chaperone $\mathrm{Chz} 1 \mathrm{p}$ regulates $\mathrm{H} 2 \mathrm{~B}$ ubiquitination and subtelomeric anti-silencing. Nucleic Acids Res 2010, 38:1431-1440.

29. Loney ER, Inglis PW, Sharp S, Pryde FE, Kent NA, Mellor J, Louis EJ: Repressive and non-repressive chromatin at native telomeres in Saccharomyces cerevisiae. Epigenetics Chromatin 2009, 2:18.

30. Gardner R, Nelson Z, Gottschling D: Ubp10/Dot4p regulates the persistence of ubiquitinated histone $\mathrm{H} 2 \mathrm{~B}$ : distinct roles in telomeric silencing and general chromatin. Mol Cell Biol 2005, 25:6123-6139.

31. Emre NC, Ingvarsdottir K, Wyce A, Wood A, Krogan NJ, Henry KW, Li K, Marmorstein R, Greenblatt JF, Shilatifard A, et al: Maintenance of low histone ubiquitylation by Ubp10 correlates with telomere-proximal Sir2 association and gene silencing. Mol Cell 2005, 17:585-594.

32. Martino F, Kueng S, Robinson P, Tsai-Pflugfelder M, van Leeuwen F, Ziegler M, Cubizolles F, Cockell M, Rhodes D, Gasser S: Reconstitution of yeast silent chromatin: Multiple contact sites and O-AADPR binding load SIR complexes onto nucleosomes in vitro. Mol Cell 2009, 33:323-334.

33. Onishi M, Liou GG, Buchberger JR, Walz T, Moazed D: Role of the conserved Sir3-BAH domain in nucleosome binding and silent chromatin assembly. Mol Cell 2007, 28:1015-1028.

34. Osborne EA, Dudoit S, Rine J: The establishment of gene silencing at single-cell resolution. Nat Genet 2009, 41:800-806.

35. Johnson A, Li G, Sikorski TW, Buratowski S, Woodcock CL, Moazed D. Reconstitution of heterochromatin-dependent transcriptional gene silencing. Mol Cell 2009, 35:769-781.

36. Katan-Khaykovich Y, Struhl K: Heterochromatin formation involves changes in histone modifications over multiple cell generations. EMBO J 2005, 24:2138-2149.

37. Hughes TR, Marton MJ, Jones AR, Roberts CJ, Stoughton R, Armour CD, Bennett HA, Coffey E, Dai H, He YD, et al: Functional discovery via a compendium of expression profiles. Cell 2000, 102:109-126.

38. Roberts CJ, Nelson B, Marton MJ, Stoughton R, Meyer MR, Bennett HA He YD, Dai H, Walker WL, Hughes TR, et al: Signaling and circuitry of multiple MAPK pathways revealed by a matrix of global gene expression profiles. Science 2000, 287:873-880

39. Zhou H, Madden BJ, Muddiman DC, Zhang Z: Chromatin assembly factor 1 interacts with histone $\mathrm{H} 3$ methylated at lysine 79 in the processes of epigenetic silencing and DNA repair. Biochemistry 2006, 45:2852-2861.

40. Weber J, Ehrenhofer-Murray A: Design of a minimal silencer for the silent mating-type locus HML of Saccharomyces cerevisiae. Nucleic Acids Res 2010, gkq689.

41. Lin Y, Kakadia P, Chen Y, Li Y, Deshpande A, Buske C, Zhang K, Zhang Y, Xu G, Bohlander S: Global reduction of the epigenetic H3K79 methylation mark and increased chromosomal instability in CALM-AF10 positive leukemias. Blood 2009, 114:651-658.

42. Strahl BD, Grant PA, Briggs SD, Sun ZW, Bone JR, Caldwell JA, Mollah S, Cook RG, Shabanowitz J, Hunt DF, et al: Set2 is a nucleosomal histone H3selective methyltransferase that mediates transcriptional repression. $\mathrm{Mol}$ Cell Biol 2002, 22:1298-1306. 
43. Louis EJ, Vershinin AV: Chromosome ends: different sequences may provide conserved functions. Bioessays 2005, 27:685-697.

44. van Leeuwen F, Gottschling DE: Assays for gene silencing in yeast. Methods Enzymol 2002, 350:165-186.

45. Oki M, Valenzuela L, Chiba T, Ito T, Kamakaka R: Barrier proteins remodel and modify chromatin to restrict silenced domains. Mol Cell Biol 2004 24:1956-1967.

46. Jambunathan N, Martinez AW, Robert EC, Agochukwu NB, Ibos ME, Dugas SL, Donze D: Multiple bromodomain genes are involved in restricting the spread of heterochromatic silencing at the Saccharomyces cerevisiae HMR-tRNA boundary. Genetics 2005, 171:913-922.

47. Zhou J, Zhou B, Lenzmeier B, Zhou J: Histone deacetylase Rpd3 antagonizes Sir2-dependent silent chromatin propagation. Nucleic Acids Res 2009, 37:3699-3713.

48. Ehrentraut S, Weber JM, Dybowski JN, Hoffmann D, Ehrenhofer-Murray AE: Rpd3-dependent boundary formation at telomeres by removal of Sir2 substrate. Proc Natl Acad Sci USA 2010, 107:5522-5527.

49. Ishii K, Laemmli U: Structural and dynamic functions establish chromatin domains. Mol Cell 2003, 11:237-248.

50. de Bruin D, Zaman Z, Liberatore R, Ptashne M: Telomere looping permits gene activation by a downstream UAS in yeast. Nature 2001, 409:109-113

51. Chiu YH, Yu Q, Sandmeier JJ, Bi X: A targeted histone acetyltransferase can create a sizable region of hyperacetylated chromatin and counteract the propagation of transcriptionally silent chromatin. Genetics 2003, 165:115-125

52. Sawada K, Yang Z, Horton JR, Collins RE, Zhang X, Cheng X: Structure of the conserved core of the yeast Dot $1 \mathrm{p}$, a nucleosomal histone H3 lysine 79 methyltransferase. J Biol Chem 2004, 279:43296-43306.

53. Mondoux MA, Zakian VA: Subtelomeric elements influence but do not determine silencing levels at Saccharomyces cerevisiae telomeres. Genetics 2007, 177:2541-2546.

54. Fourel $\mathrm{G}$, Revardel $\mathrm{E}$, Koering CE, Gilson E: Cohabitation of insulators and silencing elements in yeast subtelomeric regions. EMBO J 1999, 18:2522-2537.

55. Park JH, Cosgrove MS, Youngman E, Wolberger C, Boeke JD: A core nucleosome surface crucial for transcriptional silencing. Nat Genet 2002, 32:273-279.

56. Yu Q, Sandmeier J, Xu H, Zou Y, Bi X: Mechanism of the long range antisilencing function of targeted histone acetyltransferases in yeast. J Biol Chem 2006, 281:3980-3988.

57. Jacobson S, Pillus L: Molecular requirements for gene expression mediated by targeted histone acetyltransferases. Mol Cell Biol 2004, 24:6029-6039.

58. Donze D, Kamakaka RT: RNA polymerase III and RNA polymerase II promoter complexes are heterochromatin barriers in Saccharomyces cerevisiae. EMBO J 2001, 20:520-531.

59. VanDemark A, Kasten M, Ferris E, Heroux A, Hill C, Cairns B: Autoregulation of the Rsc4 tandem bromodomain by Gcn5 acetylation. Mol Cell 2007, 27:817-828.

60. Deniaud E, Bickmore WA: Transcription and the nuclear periphery: edge of darkness? Curr Opin Genet Dev 2009, 19:187-191.

61. Towbin BD, Meister P, Gasser SM: The nuclear envelope-a scaffold for silencing? Curr Opin Genet Dev 2009, 19:180-186.

62. Dieppois G, Stutz F: Connecting the transcription site to the nuclear pore: a multi-tether process that regulates gene expression. J Cell Sci 2010, 123:1989-1999.

63. Mekhail K, Moazed D: The nuclear envelope in genome organization, expression and stability. Nat Rev Mol Cell Biol 2010, 11:317-328.

64. Taddei A, Van Houwe G, Nagai S, Erb I, van Nimwegen E, Gasser SM: The functional importance of telomere clustering: global changes in gene expression result from SIR factor dispersion. Genome Res 2009, 19:611-625.

65. McGinty RK, Kim J, Chatterjee C, Roeder RG, Muir TW: Chemically ubiquitylated histone $\mathrm{H} 2 \mathrm{~B}$ stimulates hDot1L-mediated intranucleosomal methylation. Nature 2008, 453:812-816.

66. Suganuma T, Workman J: Crosstalk among histone modifications. Cell 2008, 135:604-607.

67. $\mathrm{Ng} \mathrm{HH}, \mathrm{Xu}$ RM, Zhang Y, Struhl K: Ubiquitination of histone H2B by Rad6 is required for efficient Dot1-mediated methylation of histone H3 lysine 79. J Biol Chem 2002, 277:34655-34657.

68. Krogan NJ, Dover J, Wood A, Schneider J, Heidt J, Boateng MA, Dean K, Ryan OW, Golshani A, Johnston M, et al: The Paf1 complex is required for histone $\mathrm{H} 3$ methylation by COMPASS and Dot1p: linking transcriptional elongation to histone methylation. Mol Cell 2003, 11:721-729.

69. Ng HH, Dole S, Struhl K: The Rtf1 component of the Paf1 transcriptional elongation complex is required for ubiquitination of histone $\mathrm{H} 2 \mathrm{~B}$. J Biol Chem 2003, 278:33625-33628.

70. Briggs SD, Xiao T, Sun ZW, Caldwell JA, Shabanowitz J, Hunt DF, Allis CD, Strahl BD: Gene silencing: trans-histone regulatory pathway in chromatin. Nature 2002, 418:498.

71. Imoberdorf RM, Topalidou I, Strubin M: A role for gen5-mediated global histone acetylation in transcriptional regulation. Mol Cell Biol 2006, 26:1610-1616.

72. Friis RM, Schultz MC: Untargeted tail acetylation of histones in chromatin: lessons from yeast. Biochem Cell Biol 2009, 87:107-116.

73. Dobi KC, Winston F: Analysis of transcriptional activation at a distance in Saccharomyces cerevisiae. Mol Cell Biol 2007, 27:5575-5586.

74. Wallace JA, Felsenfeld G: We gather together: insulators and genome organization. Curr Opin Genet Dev 2007, 17:400-407.

75. Andrulis ED, Neiman AM, Zappulla DC, Sternglanz R: Perinuclear localization of chromatin facilitates transcriptional silencing. Nature 1998, 394:592-595.

76. Maillet L, Boscheron C, Gotta M, Marcand S, Gilson E, Gasser SM: Evidence for silencing compartments within the yeast nucleus: a role for telomere proximity and Sir protein concentration in silencer-mediated repression. Genes Dev 1996, 10:1796-1811.

77. Sexton T, Schober H, Fraser P, Gasser SM: Gene regulation through nuclear organization. Nat Struct Mol Biol 2007, 14:1049-1055.

78. Akhtar A, Gasser SM: The nuclear envelope and transcriptional control. Nat Rev Genet 2007, 8:507-517.

79. Miele A, Bystricky K, Dekker J: Yeast silent mating type loci form heterochromatic clusters through silencer protein-dependent long-range interactions. PLoS Genet 2009, 5:e1000478.

80. Taddei A, Hediger F, Neumann FR, Bauer C, Gasser SM: Separation of silencing from perinuclear anchoring functions in yeast Ku80, Sir4 and Esc1 proteins. EMBO J 2004, 23:1301-1312.

81. Lebrun E, Revardel E, Boscheron C, Li R, Gilson E, Fourel G: Protosilencers in Saccharomyces cerevisiae subtelomeric regions. Genetics 2001, 158:167-176

82. Pryde FE, Louis EJ: Limitations of silencing at native yeast telomeres. EMBO J 1999, 18:2538-2550

83. Singer MS, Kahana A, Wolf AJ, Meisinger LL, Peterson SE, Goggin C, Mahowald M, Gottschling DE: Identification of high-copy disruptors of telomeric silencing in Saccharomyces cerevisiae. Genetics 1998, 150:613-632.

84. Lustig AJ, Liu C, Zhang C, Hanish JP: Tethered Sir3p nucleates silencing at telomeres and internal loci in Saccharomyces cerevisiae. Mol Cell Biol 1996, 16:2483-2495.

85. Gottschling DE, Aparicio OM, Billington BL, Zakian VA: Position effect at $S$. cerevisiae telomeres: reversible repression of Pol II transcription. Cell 1990, 63:751-762.

86. Bi X, Yu Q, Sandmeier JJ, Zou Y: Formation of boundaries of transcriptionally silent chromatin by nucleosome-excluding structures. Mol Cell Biol 2004, 24:2118-2131.

87. Marshall K, Zhang Z, Curran J, Derbyshire S, Mymryk J: An improved genetic system for detection and analysis of protein nuclear import signals. BMC Molecular Biology 2007, 8:6.

88. Rhee Y, Gurel F, Gafni Y, Dingwall C, Citovsky V: A genetic system for detection of protein nuclear import and export. Nat Biotech 2000, 18:433-437.

89. Goldstein AL, McCusker JH: Three new dominant drug resistance cassettes for gene disruption in Saccharomyces cerevisiae. Yeast 1999, 15:1541-1553.

90. Brachmann CB, Davies A, Cost GJ, Caputo E, Li J, Hieter P, Boeke JD: Designer deletion strains derived from Saccharomyces cerevisiae S288C a useful set of strains and plasmids for PCR-mediated gene disruption and other applications. Yeast 1998, 14:115-132.

91. Gardner R, Cronin S, Leader B, Rine J, Hampton R: Sequence determinants for regulated degradation of yeast 3-hydroxy-3-methylglutaryl-CoA reductase, an integral endoplasmic reticulum membrane protein. $\mathrm{Mol}$ Biol Cell 1998, 9:2611-2626.

92. Benschop JJ, Brabers N, van Leenen D, Bakker LV, van Deutekom HW, van Berkum NL, Apweiler E, Lijnzaad P, Holstege FC, Kemmeren P: A consensus 
of core protein complex compositions for Saccharomyces cerevisiae. Mol Cell 2010, 38:916-928.

93. Taddei A, Van Houwe G, Hediger F, Kalck V, Cubizolles F, Schober H, Gasser S: Nuclear pore association confers optimal expression levels for an inducible yeast gene. Nature 2006, 441:774-778.

94. van Oevelen CJ, van Teeffelen HA, van Werven FJ, Timmers HT: Snf1pdependent Spt-Ada-Gcn5-acetyltransferase (SAGA) recruitment and chromatin remodeling activities on the HXT2 and HXT4 promoters. J Biol Chem 2006, 281:4523-4531.

95. Vogelauer M, Rubbi L, Lucas I, Brewer BJ, Grunstein M: Histone acetylation regulates the time of replication origin firing. Mol Cell 2002, 10:1223-1233.

96. Kuo MH, vom Baur E, Struhl K, Allis CD: Gcn4 activator targets Gen5 histone acetyltransferase to specific promoters independently of transcription. Mol Cell 2000, 6:1309-1320.

97. Swanson MJ, Qiu H, Sumibcay L, Krueger A, Kim SJ, Natarajan K, Yoon S, Hinnebusch AG: A multiplicity of coactivators is required by Gcn4p at individual promoters in vivo. Mol Cell Biol 2003, 23:2800-2820.

98. Min J, Feng Q, Li Z, Zhang Y, Xu RM: Structure of the catalytic domain of human DOT1L, a non-SET domain nucleosomal histone methyltransferase. Cell 2003, 112:711-723.

doi:10.1186/1756-8935-4-2

Cite this article as: Stulemeijer et al:: Dot1 binding induces chromatin rearrangements by histone methylation-dependent and -independent mechanisms. Epigenetics \& Chromatin 2011 4:2.

\section{Submit your next manuscript to BioMed Central and take full advantage of:}

- Convenient online submission

- Thorough peer review

- No space constraints or color figure charges

- Immediate publication on acceptance

- Inclusion in PubMed, CAS, Scopus and Google Scholar

- Research which is freely available for redistribution

Submit your manuscript at www.biomedcentral.com/submit 